\title{
Social Reconstruction \\ As A Form of Collective Post-Conflict Reparation For The Peoples of Ambon
}

\author{
Yustina Trihoni Nalesti Dewi ${ }^{1}$, Jonathan Kwik ${ }^{2}$ \\ Soegijapranata Catholic University
}

\begin{abstract}
Ambon, the capital of Maluku in Indonesia, features a moderate and inclusive social structure, in particular with regard to differences in race, ethnicity, and religion. The capacity of the peoples, with their differences, to nevertheless live together in harmony by emphasising inclusiveness and openness, strengthened their mutual bonds together and common identity. However, a significant paradigm shift took place in 1979 with the promulgation of National Law on Village Governance. This law was an attempts at national uniformization of governance and its antipathy against local cultures that eroded traditional values. Accordingly, it could no longer save the city from descending into a religious conflict in 1999-2002. After the conflict subsided, Ambon was demographically segregated. The conflict left behind social trauma, distrustful, afraid or hateful of the opposite group. The post-conflict peace-building process was complicated heavily by these facts. Mindful of the fact that culture is a dynamic process, more support for the revitalisation of the Ambonese shared identity as a reconciliation and peace-building tool is required. Currently, this approach enjoys some momentum as the Ambonese themselves have realised that they must once again embrace their common identity instead of continually emphasising their differences. As such, it is crucial that this movement attains governmental support. This piece will report on the results of a two-year research project which studied the legal responsibilities of the Indonesian and local governments with respect to the social reconstruction of Ambon, as a form of the State's collective reparation effort vis-à-vis the Ambonese peoples.
\end{abstract}

Keywords: religious-conflict; ambon; collective-reparation; cultural; pluralism 